\title{
The Theory and Uses of Metaphor in Educational Administration and Leadership: A Rejoinder
}

\author{
Eugenie A. Samier, Reader \\ University of Strathclyde, Glasgow
}

Email: Eugenie.samier@gmail.com

\begin{abstract}
This rejoinder article first examines the foundational theories and models for metaphor use in a number of related fields, as well as in educational administration and leadership, presenting a model for analysis. Secondly, it reviews the articles in this special issue against the model proposed.
\end{abstract}

Keywords: educational administration, metaphors, educational leadership

'Is this how you want your king to rule? Should a shepherd savage his own flock?' (Epic of Gilgamesh ca. 2700 BCE)

'Our doubts are traitors and cause us to miss the good we oft might win, by fearing to attempt.' (Lucio to Isabella, Measure for Measure, Act 1, Scene 4)

'Behaviour is the mirror in which everyone shows their image.' (Goethe)

\begin{abstract}
'A leader ... is like a shepherd. He stays behind the flock, letting the most nimble go out ahead, whereupon the others follow, not realizing that all along they are being directed from behind.' (Nelson Mandela, Long Walk to Freedom)
\end{abstract}

When I was first approached about writing this rejoinder, I immediately said 'yes', assuming that my knowledge to date of literature, aesthetic analysis and research design would serve me well. That is, until I more systematically examined the literature on metaphor and its value to a number of disciplines from which educational administration and leadership draw, finding that metaphor is a much deeper linguistic and conceptual phenomenon than I had 
thought. The first section of this article provides an overview of theory and method from which my perspective and approach are constructed, which is then applied in the second section reviewing the articles in this special issue.

Metaphor Theories and Methods

On a fundamental conceptual and linguistic level, all knowledge and language is metaphoric (Brown 1976, 1977), argued by some to be central to human cognition and verbal and nonverbal communication, and initially recognised by Aristotle as the way that reality is represented in language (Fauconnier and Turner 2002), and playing an important role in Kant's theory of concept formation (O'Neill 1989). It is partly for this reason that people hold values in their language implicitly, contributing to problems of discrimination in gender, ethnicity, etc. On its most fundamental level, metaphor is a means by which concept formation takes place, where knowledge is constructed, and models are created (Arbib and Hesse 1986), Lakoff and Johnsen (2003) claim that most of our thinking and conceptual knowledge is metaphoric, underlying every day and scholarly knowledge and language use. Linguistic models of metaphor have tended towards cognitive models, although Caspi (2018) effectively argues that it is also shaped by affect in ways that lend metaphoric study to psychoanalysis, itself metaphorically constructed.

In sociology, also, some approaches are grounded in metaphor as a substratum upon which understanding and knowledge are built. For example, Landau, Robinson and Meier $(2014,4)$ argue that we both understand and experience social concepts through metaphor in far more fundamental ways than we are used to appreciating on a conscious daily basis:

- I can see your point (understanding is seeing)

- I'll keep that in mind (the mind is a container)

- Christmas is fast approaching (events are moving objects)

- That is a heavy thought (thoughts are objects with weight)

- I feel down (feelings are vertical locations)

- The national economy veered off course (economy as a vehicle)

- I devoured the book, but I'm still digesting its claims (ideas are food)

- Her arguments are strong (arguments are muscle force)

- I'm moving forward with the book (progress is forward motion) 
For Bourdieu (1977), 'The mind is a metaphor of the world objects which is itself but an endless circle of mutually reflecting metaphors' (91). Ricoeur (1978) emphasises more the hermeneutic value of metaphor inhering in its ability to re-describe reality, reflecting not only external objective reality but our interpretations of it influenced by many personal and social factors. Katz (2017) has recently explored the role of metaphor in our representations of experience, our unconscious activity, conscious understanding and communication and the inter-personal world influenced by these. These dimensions shape our personalities, values, social belief systems, motivation and ways of working. The contextual perspective of metaphor is also promoted by Ritchie (2006) to examine how explicit and implicit communication, social situation and cultural setting influence the metaphors from which our thinking and knowledge is formed and framing our understanding and research of social institutions like education in a society.

In administration and management studies, there have been several decades of work on the value of metaphor in generating theory and providing interpretation and analysis including authors like Weick (1989), as well as a complex model proposed by Tsoukas (1991) for assessing how metaphors work in the field in providing new and insightful ways of understanding. Many metaphors have been used from the 'servant' to the public in the traditional 'mandarin' public administration, supplanted through neoliberalism and the New Public Management through managerialism and its avatar, the entrepreneur, of the public sector. Metaphors are used to both idealise the way one works as well as provide a structured means, with the 'craft' tradition used frequently drawing on the apprenticeship guild system (Heracleous and Jacobs 2011) and the use of strategic planning derived from a military origin (Levy, Alvesson and Willmott 2003). More recent metaphors have been used for critical purpose, for example, to describe contemporary conditions in so many organisations under stress like the 'silent assassin' metaphor used by Nikolova et al. (2018) to describe job insecurity produced by negative dynamics in the employee-leader relationship.

Leadership studies has also contributed discussion on metaphors of styles and types of roles such as Greenleaf's (1997) servant leadership model, and Swint's (2011) roles and leadership styles: Machiavellians, empire builders, kingmakers, spies, silver-tongued devils, generals, rebels, the truly evil, the fixers and the schemers. Metaphor is also implicit in much of the discussion about leadership that invokes a 'strong man', saviour or heroic role for those 
expected to improve or turn around organisations, and by association with historical figures like Churchill or Boudica (or Pallas Athena) used as metaphors provide value, vision and motivation (Charteris-Black 2005), create legitimacy and connect inner vision with external reality while satisfying psycho-emotional needs (Charteris-Black 2007). Metaphors for leadership have different functions: being constructive in providing identity, a sense of value and community or purpose; used to critique bad or destructive leadership and provide a defence mechanism for those affected; being negative and destructive in an organisation used for political purpose; and as a fantasy to enhance identity rather than reflect work practices (Sveningsson and Larson 2006). This range of the moral, developmental, support, commanding and efficiency dimensions of leadership are explored by Spicer and Alvesson (2011) as saint, gardener, buddy, commander, cyborg and bully in examining the complexity and multi-faceted nature of the role aimed at understanding and interpretation of leadership in context. There are also metaphors used to classify dysfunctional forms like that used by Furnham (2010) to denote toxic, bad and incompetent leadership in The Elephant in the Boardroom.

Organisation studies has probably contributed the most through an examination of metaphors in analysing organisational dynamics. One of the earliest is that of Gareth Morgan's (1997) Images of Organization, using root metaphors analytically to classify approaches and critiques like machine, organism, brain, culture and psychic prison, complex categories within which one can create descriptive metaphors that underpin the process by which theories are created producing frameworks of understanding. This text has served as a foundation for many others investigating how metaphors arise in both scholarly analysis and organisational life, how they influence behaviour and attitudes, and how they can be used in management (Grant and Oswick 1996). This was followed by Imaginization: New Mindsets for Seeing, Organizing and Managing (1997) discussing ways in which organisational metaphors and the process of creating them contribute to scholarship, shape and even limit the way we see and interact with the world. He contends that while 'root metaphors' provide a deeper and broader understanding, there are also 'surface' or 'decorative' metaphors that are new 'cute' ones that only superficially embellish communication.

Despite generating criticism for being relativist and pluralist epistemologically, and not effectively critiquing issues of power and domination (Örtenblad, Putnam and Trehan 2016), Morgan's work has been heavily used for research in many fields, including educational 
administration. Metaphor has been promoted as a way of understanding and managing organisations and the way that people behave and the attitudes they express. It has been used also as a way of critiquing organisations and has generated a number of research methods aimed at metaphoric study such as forms of story-telling (Grant and Oswick 1996), most used in hermeneutic, rhetoric, discourse and symbolic interactionist studies (Chmielecki and Sułkowski 2017). A number of styles or types of organisational culture emerged heavily influencing educational administration and leadership: Quinn and Rohrbaugh's (1983) clan, entrepreneur, hierarchy (or, bureaucratic) and market forms; and Deal and Kennedy's (1982) organisational politics roles of whisperers, gossips, secretarial sources, spies, and cabal members. The nature of professional roles has also been examined for functional metaphors that enable people to define their identities, frame accomplishments, and position themselves within the organisation such as Inkson's (2006) inheritance, cycle, fit and journeys, and more recently by Liljegren and Saks (2017) with a more critical view encompassing power and political metaphors of 'slaying the minotaur,' 'boa constrictor,' 'zoos,' 'circuses,' and 'engineering the soul'.

Cornelissen (2004) proposes a more integrated and developed model of organisational metaphor, consisting of theatre language relevant to actor, scene, script, staging since it allows for an examination of identity and role enactment including its ritualistic and dramaturgical qualities, plotting, audience, symbolic dimensions and the dynamics of 'real time' organisational life. Drawing on the work of Morgan (1980) and Alvesson (1993) he proposes governing rules for metaphors producing an 'emergent meaning structure' that consist of a functional balance of similarity and dissimilarity for the metaphor to be understandable and provide insight, and aptness in terms of fit of the metaphor with the subject (712). It is this approach from which 'performativity' is drawn in examining administrator and leader behaviour and style. Dance and choreography have been used to explore embodied forms of knowing, movement and non-verbal communication as well as methods of practice in organisational life, roles and relationships (Matzdorf and Sen 2016; Yams and Srhoj 2018). The use of metaphoric analysis is also part of the aesthetics of organisation, providing a means of expression personally and forming the stories, myths and rituals of organisational life, connections to other and social structures and forces, and the construction of identity (Strati 2016). 
In educational administration and leadership, too, metaphors are commonplace, for example, Murphy's (2002) tripartite set of roles for leaders as stewards, educators or community builder. However, only a few have examined the nature and role of metaphor in our understanding and practices of the administrative and leadership roles. Sergiovanni (1994) was one of the earliest demonstrating that a metaphor shift from management and economics models to a community metaphor necessarily changes educational administration substantially. Cherry and Spiegel (2006), drawing on Jungian theory, explored a number of archetypes, or metaphors, for leadership in school change that have functional purpose: the touchstone, advocate, gardener, parent, and spiritual guide. More recently, Lumby and English (2010) have compiled many of the metaphors used for leadership, all of which apply to education, at one time or another or in one setting or another. For Lumby and English (2010), metaphor is fundamental to thinking and language and shapes our worldviews as well as our construction of identities and roles, but in both constructive and beguiling ways, while often quite unconsciously assuming a literal reality to metaphor, reviewing some of the dominant types such as the machine, accountancy, warrior, theatre, and religion, ending with lunacy to describe the more pathological forms of leadership.

Metaphor has been used to critical purpose in the field, for example, Gunter's critique of a common but failing human resource management model in an article called 'Jurassic Management' (1995), Craig's (2003) critique of the bureaucratic character that schools often take in Narrative Inquiries of School Reform through narratives of subjects' human drama as in the case of the 'dueling banjos' and the case of the 'dragon in school backyards'. In some cases metaphors have operational effect in hindering and helping schools, seen in Wincek's (1995) account of 'vision,' 'families,' 'teams,' and 'vision-keeper.' Metaphor is used also in examining the negative, incompetent, abusive and toxic forms of administrative and leadership roles and incumbents, for example, in Henry Giroux's (2016) Dangerous Thinking in the Age of the New Authoritarianism where neoliberalism's effect on education is a 'poison' and higher education has become a 'dead zone'. One of the most powerful metaphors, more often used as a critique, is education under neoliberalism operating through a market model (e.g., Henig, 1994).

In higher education a number of metaphors have been used in relation to extra-academic values like Benda's (1969/1927) The Treason of the Intellectuals and internal cultural and informal structures within and among disciplinary units like Becher's (1989) book on 
academic tribes using a traditional societal structure to map them out. The changing types of metaphors used indicate the changing nature, values, structures, ideologies and relationships with other social institutions over time such as economic and financial control and pathology due to neoliberalism and the market model. Silander and Haake (2017), for example, examining the variable use of gold-digger, supporter and profiler across the university hierarchy in conforming to or resisting a government agenda to shift academic research towards 'utility,' or Giroux's (2007) The University in Chains to describe the relationships within the military-industrial-academic complex. Metaphors are often implicitly conveyed and unconsciously held, found by Jameson (2007) to include in her study of their use in postcompulsory UK leadership to consist of a voyage of discovery, a performance, an art, a bank, market, religion, garden and war.

One limitation to the literature is that most discussions reflect primarily Western (mostly Anglo-American) social experience, not the devastating conditions in many countries going through wartime conditions, humanitarian crises or operating under dictatorships. Since metaphors are culturally constructed, they will vary in meaning and usefulness, depending on the context in which they are constructed and applied due to values, culture, political system, and characteristics of other social institutions that affect styles of social interaction and organisational hierarchies. Gibson and Zellmer-Bruhn (2001) investigated the metaphors for cross-cultural teamwork finding that variance in metaphor reflects the characteristics identified in cross-cultural management that produce task definition, social hierarchy, loyalty, conceptions of authority, behavioural patterns, and values with major metaphors conceptualised differently from culture to culture: family, sports team, the military, associational relationships, and community. If one were to take a broader international perspective, then many other systems of metaphors become relevant reflecting the environment in which people live (Kövecses 2015).

Muna (2018) suggests seven metaphors that work for management in the Arab world, that have particular resonance: the candle, iceberg, tripod, transit lounge, mosaic, helicopter, and bridge. Albakeri (2014) has taken issue with the 'iceberg' concept used for organisational culture, arguing that the tree metaphor works much better in traditional Arab societies, particularly those with desert environments, although one could argue might also work better in any human environment. The tree metaphor is seen to be more appropriately organic in the relationship between how a person develops and the environment in which they are 
situated. In the United Arab Emirates, the founder of the country Shaikh Zayed al Nahyan used the tree metaphor, in part derived from an intense tree-planting programme that could change the micro-climate that he transferred to creating a society that could nourish people into a multicultural harmonious mix as a sustainable social environment in which they could thrive.

Metaphor works at the heart of theory-building for research and critique, claimed by Morgan (1980) to define approaches and schools of thought which provide a taken-for-granted reality and assumptions made that give knowledge symbolic form and are central to the creative nature of scholarship. Therefore, metaphors can be used to conceptualise and interpret many levels from the individual, the social interactional, organisational, social institutional and international levels. They also represent aspects of roles (leader, administrator, follower, student), structures and processes in organisational life, as well as the styles of organisational culture and politics that inhere. From a disciplinary level they can also reflect the psychological, social, cultural, political (e.g., power relations), and economic (e.g., the 'entrepreneur') as well as draw on the fine arts for performative and creative qualities. Metaphor also provides a qualitative research method that can better capture the inner world of participants through their personalities, beliefs, values, concepts and their fears, aspirations and ambitions (Argyropoulou and Hatira 2014). Roberts and Woods (2018) argue in their examination of collage for education leadership research that metaphor creation captures a broad experiential range, and Paranosic and Riveros' (2017) analytic use of exploring how school department heads understand their roles through the metaphors they use can illuminate the social construction of their roles.

Metaphor is a fundamental dimension of language and meaning construction, a reflection of an individual's perspective, of cultural norms, and which can also be generated within organisations from personality, styles of social interaction, organisation culture and politics, and the experiential. Metaphors have theoretical value in providing frameworks, classification of information, and interpretation of data and meaning, but also have social value in capturing and expressing how we live organisationally in our identity, personal values, and roles as well as resistances and critiques. From this foundation it is possible to derive a number of qualifying criteria for metaphor use: 
- Understanding the nature of metaphor - underlying and explicit characteristics for thinking, representation, language, and types of metaphor

- Theories of using metaphor - recognising similarities/dissimilarities, the boundaries or limits, and contextual constraints, as well as romanticised versus more realistic or critical forms - metaphors can be instruments of domination (like leadership as male or white), or by neoliberalism and other value systems that are problematic, autocratic or damaging

- For analytic and interpretive purpose, including reflexivity by the researcher, elucidating what may be unconsciously understood in the organisation in terms of its cultural health, political tensions, and sometimes contradictory dynamics from the individual level to the macro-level.

- As a methodology for positivist, interpretive and critical research, but more commonly used in grounded theory, hermeneutics and phenomenology

- As positive and negative critiques of systems and experience; representing service to others, society and humanity, as well as resistance, challenge and critique of dominating systems or power imbalances along gender, ethnicity and other lines.

\section{Review of the Articles}

The articles in this issue reflect many of the criteria for metaphor use, some more theoretically oriented than others, and some more focussed on the construction of a particular metaphor either as a critical device by the researcher, or employed by participants in conveying their experiences.

Pat Thomson's 'Thinking about the school most of the time' provides a substantial discussion about the nature and use of metaphor in thinking and speech, including a short overview of various disciplinary critiques and examples from the educational administration and leadership literature in preparation for the metaphor she proposes, the artistic studio, as a means by which school principals can better sustain their professional practice and cope with the many pressures on school systems internationally. Limitations to this metaphor lie predominantly in two areas: first, school heads who have too effectively internalised the market and accountability regimes; secondly, the artistic studio is not always transferable to cultures where the requisite values and practices needed for the metaphor, or where conditions allowing for its use such as war, humanitarian crises and invasion exist. However, 
the studio as a practice of reflexivity and adopting an openness from which to adopt a perspective of unknowing that allows for a fresh 'professional and personal learning' unencumbered by the demands of the position. While providing a means for stepping out of constrained thinking, studio practice allows one to re-encounter complexity, ambiguities and contextualities, and the critical reflections and dialogues, lost as socialisation and the internalisation of one's role takes place.

Even if the artist studio metaphor is not transferable to some cultures, there are subjective and social spaces that can provide the same opportunity for rethinking education, its structure and role, and the place that an individual may have in it through a critique and self-expression and possibly the reinterpretation and redefinition of one's professional practice. In this way, too, the studio, like much art, can be a politicised space in which dominating values can be set aside or rejected such as the neoliberal market model in order to pursue social movement activities and social justice, but also has resonance for expatriates who have been operating as globalisation agents. Where much of the discussion in Thomson's article focusses on the reflections identified by Day (2000) in creating 'good' and 'effective' leadership, there is value also in pursuing a critical theory end challenging the prevailing conditions or for those in developing countries, envisaging multicultural and inclusive environments and taking a stronger postcolonial view in how knowledge, organisational cultures and roles are constructed. The boundaries of the artist's studio, in this case, lie where art and artists have contributed to propaganda, the celebration of power and authority, and the rule of the state in dictatorships and oligarchies. However, even these boundaries are a valuable aspect of the metaphor engaging one in critical reflection on who one is actually serving and what underlying values are driving education.

Deborah Netolicky's article, 'Redefining the School Leader through Unexpected Metaphor: The Cheshire Cat" is one I was looking forward to reading for personal reasons - from my early memories as a child of many hours reading Alice's Adventures in Wonderland and looking at the illustrations. This article also begins with a strong discussion of theory and the conceptual approach of the author focussed on the value of metaphor as an analytical and critical tool in research and understanding of the school leadership role. Much like the artist's studio, the Cheshire Cat has archetypal significance with corollaries in other cultures - what comes to mind are the Arabian Nights containing characters with similar form and significance. Netolicky has concentrated on literary metaphor, among others, that arise in 
interview data in illuminating leadership contexts and experiences, in this case, the Cheshire Cat as a way of characterising the nonsensical and absurd aspects of professional life that occur in education and which depart from the many views of it as rational, meaningful, and planned and the heroic image of school leaders and a means of examining power relationships and various kinds of shared leadership. This discussion positions the metaphor in the context of other scholarship and the lacunae of literature on how leaders perceive their leader selves and identities, particularly that of middle leaders.

In this case, the metaphor emerged through researcher interpretation of hermeneutic data, finding a composite character image to collectively represent the emergent themes of several participants' experiences in school leadership that are not always overt, explicit, manifest, or visible. Another aspect of the Cheshire Cat is the relationship with Alice that is advisory and suggestive rather than directive. The strength in the use of this metaphor lies in its complexity, conceptualised and used as a multidimensional representation without straining credulity. Also presented is the extraction of theory from the empirical, into a form that allows for capturing the variable practices of school leaders who have many roles to perform, many types of relationship to fulfil and varying degrees of authority, contingent on the circumstances and individuals involved at any point in time described by Netolicky as a 'fluidity' in leadership approaches on a directive-collaborative continuum and a 'balance' of factors and modes of practice. What is possibly most valuable in this article are a set of questions the researcher must ask about the choice of metaphor and recognising its limitations, in this case regarded by the author as one not intended for socio-cultural and political critique.

Katrina MacDonald's article on 'Robinson Crusoe and the Island of Despair' uses the story as a metaphor in researcher reflexivity for a biographical study of principalship following principles of social justice and equity in pursuing goals of addressing social disadvantage. In this case, the metaphor contains within it the colonisation critique embedded in Robinson Crusoe of British imperialism through religious, economic, and psychological factors that serves as a valuable trope in interpreting a case study of a self-identified social justice leader. A more explicit critique of the colonising character of Robinson Crusoe is portrayed in the 1975 film, Man Friday, where a postcolonial purpose is evident through the film's presentation of Friday's perspective. I would argue here that using metaphor to advance 
interpretation works particularly well given the Bourdieuian design of the study that collected information on field, habitus and capital that lend themselves to metaphoric analysis.

MacDonald, like the previous two authors reviews relevant theoretical literature on metaphors for scholarly purpose in terms of interpretive method, grounding the study in Lakoff and Johnson's (2003) Conceptual Metaphor Theory recognising Bourdieu's claim about the unconscious metaphors used by researchers and to recognise the ideologies inherent in metaphors connected to particular contexts. In this case, the notion of the individualist heroic leader, a missionary zeal, and cultural imperialism as forms of habitus are investigated through a principal biography. The emphasis on the interpretation of the subject's discussions, through a Crusoe metaphor emphasises unconscious dimensions of the subject's self-described role is that of a heroic saviour, engaged in a, superior, missionary perspective and an imperialist silencing of the aboriginal voice in his school connected to values of social justice. In other words, the metaphor brings to the surface a deconstructing perspective more akin to Friday's role in the film version of the story.

Megan Maguire and Annette Braun's policy narration paper is more elusive as a discussion of metaphor in understanding headteacher practices. There is little discussion of the nature, forms and uses of metaphor, which reduce the effectiveness of the paper and a lack of critical awareness of this approach and a positioning of metaphor in the context of the various theories and uses available in the literature - requiring the reader to deduce the conceptions of metaphor employed by the authors. What seems to be the 'metaphor' employed is that headteachers act as policy narrators - which causes a problem in understanding. All administrators are part of the policy process (see Howlett and Ramesh 2003; Parsons 1995), needing to interpret and implement policy and contribute to its development. So in a very real, objective sense, headteachers are not metaphorically policy actors or persuaders, nor are all forms of narration storytelling. More effective use could be made of the 'storytelling' part of the policy narrator metaphor and the policy 'actor' metaphor which bring a long and strong tradition of literary and theatre modes of discussion, as well as critique of the populist literature on leadership referred to briefly, where the underlying values, ideologies and social interactions could have been more exposed, and the more subtle metaphors embedded in their narrative drawn out analytically for their implications. The narrative text of the subjects of the study are packed with metaphors that are not interpreted or analysed. The article remains on a descriptive level without use of deeper metaphor analysis of alluded to conflict, tension, 
economic values orientation, political solidarity with communities, advocacy, and considerations of social justice and welfare.

Christine Grice's 'Spies, Surveillance, and Distributed Pedagogical Middle Leadership' is a promising article, given the many issues that have arisen over the last few decades regarding employee surveillance, the use of spies in some accountability regimes and organisational politics, security problems with digital systems, and the use of the educational system to a political security and military purpose (e.g., Giroux 2007, 2016; Neocleous 2008; Samier 2014). In this case, the study examines metaphors employed by the participants of an espionage character reflecting their attitudes towards the politics of pedagogy and school leadership. However, there is no discussion in the article about metaphor theory and how one can use and interpret metaphors, which leads also in this case to an undeveloped analysis of these types of metaphors employed by the participants, nor a full development of the implications of these aspects of organisational politics for human rights, constitutional rights, labour law, and professional and educational ethos. This is one part of the metaphoric analysis - what underlying values and social institutional arrangements and practices are implicated?

The metaphors here are promising given the politics of government, the shifts in neoliberal surveillance of professional practice, and the shifts towards populist nationalism occurring in many countries which relies on espionage systems turned inwards against its own populations and institutions - the politics that play out in educational politics are indicators of much deeper societal ills and problems. However, one requirement for using metaphors is a close study of the character of the world from which the metaphor is chosen, in this case the security intelligence world that makes necessary reliable sources on how this world functions. While participants may not be consciously aware of the particularities of the world from which they draw their metaphors, one cannot dismiss the unconscious knowledge (and anxiety) that are carried in their allusions. In this case, the spying and surveillance world from which the metaphors are drawn is not investigated for an accurate use of relevant terminology in order to analyse more deeply the values, practices and social relations inherent in that world. While the participants may refer to the James Bond fantasy world of spying, an analysis of the metaphor needs to dig much deeper into the intelligence world than a rather kitischified presentation of professional roles that these movies convey such as what constitutes an intelligence officer different from collaborator and different from spy (rather 
than conflating roles and even types of intelligence agencies), all features that exist in educational politics but need to be carefully and accurately differentiated. There are many detrimental and serious aspects of spying and surveillance in organisations that require more than a heavily stylised romanticised view, and which are alluded to by the participants. A related metaphor of 'empire building' is partly developed, locating it in the neo-imperialism of globalised neoliberalism, but this metaphor also has a very long heritage in administrative studies which long predated neoliberalism and which still resonate with meaning even if combined with the current political ideology.

Amanda Heffernan's 'punk rock principal' article brings into the metaphor discussion for educational administration and leadership a well-established type of metaphor - drawing from the performative and artistic realms in a similar way to De Pree's (1993) Leadership $J a z z$, and with more depth of analysis studies that have explored the conductor metaphor (Koivunen 2006), but with intriguing new dimensions and updating the metaphor use to the rock music world. The article reviews some of the key literature on the use of metaphor in leadership studies, including identifying important gendered and political aspects, positioning the paper in metaphor theory, with a strong discussion on the nature and use of metaphor in organisational, administrative and leadership studies regarding a number of personal, political and economic topics, including those of social justice and morality. The 'punk' metaphor is classified accurately as one of those avant-garde movements with challenges to the status quo and a reform-type agenda for social institutions and the change of social norms, discussed not only in terms of its obvious features, but also in its more implicit and nuanced characteristics, linked analytically to Foucault's (2007) notion of 'counter-conduct' in resisting policy regimes and changes and Lyotard's (1984) conception of performativity although these could be more developed in the article.

The longest participant passage is one in which the metaphor of a rhythm guitarist in a rock and roll band is presented, itself a very rich metaphor for politico-aesthetic analysis. It is from this foundation that a further proposition of using a 'punk rock' metaphor is explored by researcher's to examine more closely the socio-political resistance of the participant which can 'profitably' extended to other participants and scholarship in the field, particularly against neoliberal agendas and their accountability regimes. One of the values of using metaphor, as in the case of this article, is that it can evoke in the reader's mind similar metaphors of value. Throughout my reading, I kept hearing in my mind Pink Floyd's The 
Wall, an equally valuable form of resistance to many kinds of dictatorial regimes, whether institutional, political, economic or cultural, as well as Red Rider's 'Lunatic Fringe.'

\section{Conclusion}

There are a number of conclusions one can draw from reviewing metaphor literature and its discussion in the papers in this collection. First, the fundamental nature of metaphor in thought and language needs to be better recognised in the field, particularly as it is both explicitly and implicitly conveyed in a non-reflexive manner as well as critical manner. Metaphors chosen consciously and unconsciously both advance our interpretations of experience, but also limit them. As illustrated in these papers, metaphor provides a strong interpretive method and analytical approach that can illuminate leadership experience in its complexity - from individual levels of experience, through the organisation and then to contextual and even global factors. Metaphors need to be much more seriously researched examining the world from which they come, their quality, the depth of understanding of participants and the researcher, and the values they promote, for example, those used in kitsch-level populist leadership guides and books that further chain one to the status quo.

There are questions, though, of the validity of many metaphors, particularly for international used. Metaphors need to be discussed in the contexts from which they come rather than presented as universally applicable. Kövecses (2005) demonstrates that there are metaphors with universal use and meaning, such as many of those related to anger, but there are many forms of metaphor that differ because of socio-cultural experience and values. So, it is on this metaphor level of conceptualisation and language that internationalisation of the field also needs to take place, and some reflexivity in the field on how universal one can assume the literature to be.

What is also referred to in some of the articles to varying degrees of analysis is the current Zeitgeist, partly connected to the globalisation of neoliberalism, but also now means dangerous shifts taking place towards the 'strongman' leader image arising in nationalist and populist movements. Another major change is the digitalisation of our personal and professional lives and those of our students that brings with it critical metaphors that need desconstruction, like that of connectivity (Mosco 2000) currently promoted as a means of teaching, as well as equally powerful counter-metaphors of analysis. 
References

Albakeri, F. 2014. Modelling of senior staff characteristics: Towards an optimum public administration system in the United Arab Emirates, unpublished doctoral thesis, British University in Dubai, Dubai, United Arab Emirates.

Alvesson, M. 1993. "The play of metaphors.” In Postmodernism and Organizations, edited by J. Hassard and M. Parker. London: Sage.

Arbib, M. and M. Hesse. 1986. The Construction of Reality. Cambridge: Cambridge University Press.

Argyropoulou, E. and K. Hatira. 2014. "Metaphors and drawings as research tools of head teachers' perceptions on their management and leadership roles and responsibilities." European Early Childhood Education Research Journal 22 (4): 496-512.

Becher, T. 1989. Academic Tribes and Territories: Intellectual Enquiry and the Cultures of Disciplines. London: Open University Press.

Benda, J. 1969/1927. The Treason of the Intellectuals. New York: W. W. Norton.

Bourdieu, P. 1977. Outline of a Theory of Practice. Cambridge: Cambridge University Press.

Brown, R. 1976. "Social theory as metaphor." Theory and Society 3 (2): 169-197.

Brown, R. 1977. A Poetic for Sociology. Cambridge: Cambridge University Press.

Caspi, T. 2018. "Towards psychoanalytic contribution to linguistic metaphor theory." International Journal of Psychoanalysis. Advance online publication. https://doi.org/10.1111/1745-8315.12683.

Charteris-Black, J. 2005. Politicians and Rhetoric: The Persuasive Power of Metaphor. Houndmills: Palgrave Macmillan.

Charteris-Black, J. 2007. The Communication of Leadership. London: Routledge.

Cherry, D. and J. Spiegel. 2006. Leadership, Myth and Metaphor. Thousand Oaks: Corwin.

Chmielecki, M. and Ł. Sułkowski. 2016. Metaphors in Management. Frankfurt am Main: Peter Lang.

Cornelissen, J. 2004. "What are we playing at? Theatre, organization, and the use of metaphor." Organization Studies 25 (5): 705-726.

Craig, C. 2003. Narrative Inquiries of School Reform. Charlotte, NC: Information Age Publishing.

Deal, T. and A. Kennedy. 1982. Corporate Cultures. Reading, MA: Addison-Wesley.

De Pree, M. 1993. Leadership Jazz. New York: Bantam. 
Day, C. 2000. "Effective leadership and reflective practice.” Reflective Practice, 1(1): 113127.

Fauconnier, G. and M. Turner. 2002. The Way We Think. New York: Basic Books.

Foucault, M. 2007. Security, Territory, Population: Lectures at the Collège de France, 19771978. Basingstoke: Palgrave Macmillan.

Furnham, A. 2010. The Elephant in the Boardroom: The Causes of Leadership Derailment. Houndmills: Palgrave Macmillan.

Gibson, C. and M. Zellmer-Bruhn. 2001. "Metaphors and meaning: An intercultural analysis of the concept of teamwork." Administrative Science Quarterly 46 (2): 274-303.

Giroux, H. 2007. The University in Chains: Confronting the Military-Industrial-Academic Complex. Boulder: Paradigm.

Giroux, H. 2016. Dangerous Thinking in the Age of the New Authoritarianism. Abingdon: Routledge.

Grant, D. and C. Oswick. eds. 1996. Metaphor and Organizations. Thousand Oaks: Sage.

Greenleaf, R. 1997. “The servant as leader.” In Leadership, edited by R. Vecchio, 429-438. Notre Dame, IN: University of Notre Dame Press.

Gunter, H. 1995. "Jurassic management: Chaos and management development in educational institutions." Journal of Educational Administration 33 (4): 5-20.

Henig, J. 1995. Rethinking School Choice: Limits of the Market Metaphor. Princeton: Princeton University Press.

Heracelous, L. and C. Jacobs. 2011. Crafting Strategy: Embodied Metaphors in Practice. Cambridge: Cambridge University Press.

Howlett, M. and M. Ramesh. 2003. Studying Public Policy. Oxford: Oxford University Press.

Inkson, K. 2007. Understanding Careers: The Metaphors of Working Lives. Thousand Oaks: Sage.

Jameson, J. 2007. "Metaphors of leadership in post-compulsory education.” International Journal of Knowledge, Culture and Change Management 6 (8): 179-187.

Katz, S. 2017. Contemporary Psychoanalytic Field Theory: Stories, Dreams, and Metaphor. Abingdon: Routledge.

Koivunen, N. 2006. “Auditive leadership culture: Lessons from symphony orchestras.” In The Social Construction of Organization, edited by D.-M. Hosking and S. McNamee. Copenhagen: Business School Press.

Kövecses, Z. 2005. Metaphor in Culture: Universality and Variation. Cambridge: Cambridge University Press. 
Kövecses, Z. 2015. Where Metaphors Come From. Oxford: Oxford University Press.

Lakoff, G. and M. Johnsen. 2003. Metaphors We Live By. London: University of Chicago Press.

Landau, M., M. Robinson, and B. Meier. eds. 2014. The Power of Metaphor: Examining Its Influence on Social Life. Washington DC: American Psychological Association.

Levy, D., M. Alvesson, and H. Willmott. 2003. "Critical approaches to strategic management.” In Studying Management Critically, edited by M. Alvesson and H. Willmott. London: Sage.

Lijegren, A. and M. Saks. eds. 2017. Professions and Metaphors. Abingdon: Routledge. Lumby, J. and English, F.W. 2010. Leadership as Lunacy, and Other Metaphors for Educational Leadership. Thousand Oaks: Corwin.

Lyotard, J.-F. 1984. The Postmodern Condition Manchester: Manchester University Press. Man Friday. 1975. Dir. Jack Gold. ABC Entertainment.

Matzdorf, F. and R. Sen. 2016. "Demanding followers, empowered leaders: Dance as an 'embodied metaphor' for leader-follower-ship.” Organizational Aesthetics 5 (1): 114130.

Morgan, G. 1980. "Paradigms, metaphors and puzzle solving in organizational theory." Administrative Science Quarterly 25: 605-622.

Morgan, G. 1986. Images of Organization. Thousand Oaks: Sage.

Morgan, G. 1997. Imaginization: New Mindsets for Seeing, Organizing and Managing. San Francisco: Berrett-Koehler.

Mosco, V. 2000. "Webs of myth and power: Connectivity and the new computer technopolis." In The World Wide Web and Contemporary Cultural Theory, edited by A. Herman and T. Swiss. New York: Routledge.

Muna, F. 2018. Seven Metaphors on Management: Tools for Managers in the Arab World. Abingdon: Routledge.

Murphy, J. 2002. "Re-culturing the profession of educational leadership: new blueprints." Educational Administration Quarterly 38 (2): 176-191.

Neocleous, M. 2008. Critique of Security. Edinburgh: Edinburgh University Press.

Nikolova, I., B. Van der Heijeden, L. Låstad, and G. Notelaers. 2018. “The 'silent assassin' in your organization?" Personnel Review 47 (6): 1174-1193.

O’Neill, O. 1989. Constructions of Reason. Cambridge: Cambridge University Press.

Örtenblad, A., L. Putnam, and K. Trehan. 2016. “Beyond Morgan's eight metaphors.” Human Relations 69 (4): 875-889. 
Paranosic, N. and A. Riveros. 2017. "The metaphorical department head: Using metaphors as analytic tools to investigate the role of department head." International Journal of Leadership in Education 20 (4): 432-450.

Parsons, W. 1995. Public Policy: An Introduction to the Theory and Practice of Policy Analysis. Cheltenham: Edward Elgar.

Quinn, R. and J. Rohrbaugh. 1983. "A spatial model of effectiveness criteria: Towards a competing values approach to organizational analysis." Management Science 29 (3): 363-377.

Ricoeur, P. 1978. The Rule of Metaphor: The Creation of Meaning in Language. London: Routledge.

Ritchie, L. 2006. Context and Connection in Metaphor. Basingstoke: Palgrave Macmillan.

Roberts, A. and P. Woods. 2018. "Theorising the value of collage in exploring educational leadership.” British Educational Research Journal. Advance online publication. https://doi.org/10.1002/berj.3451.

Samier, E.A. 2014. Secrecy and Tradecraft in Educational Administration. Abingdon: Routledge.

Sergiovanni, T. 1994. "Organizations or communities? Changing the metaphor changes the theory." Educational Administration Quarterly 30 (2): 214-226.

Silander, C. and U. Haake. 2017. "Gold-diggers, supporters and inclusive profilers: Strategies for profiling research in Swedish higher education." Studies in Higher Education, 42(11), 2009-2025.

Spicer, A. and M. Alvesson. 2011. “Metaphors for leadership.” In Metaphors We Lead By, edited by M. Alvesson and A. Spicer. Abingdon: Routledge.

Strati, A. 2016. "Aesthetics and design: An epistemology of the unseen." In The Routledge Companion to Philosophy in Organization Studies, edited by R. Mir, H. Willmott and M. Greenwood. Abingdon: Routledge.

Sveningsson, S. and L. Larson. 2006. "Fantasies of leadership: Identity work." Leadership 2 (2): 203-224.

Swint, K. 2011. The King Whisperers. San Francisco: Union Square.

Tsoukas, H. 1991. "The missing link: A transformational view of metaphors in organizational science." Academy of Management Review 16: 566-585.

Weick, K. 1989. “Theory construction as disciplined imagination.” Academy of Management Review 14: 516-531. 
Wincek, J. 1995. Negotiating the Maze of School Reform. New York: Teachers' College Press.

Yams, N. and D. Srhoj. 2018. "Is this choreography? Choreographing conditions for innovative practice in everyday work." Organizational Aesthetics 7 (1): 24-45.

Biographical Note: (200) 